\title{
Effectiveness of electromagnetic and electro-osmosis methods for the treatment of rising damp
}

\author{
Julie Desarnaud ${ }^{\mathrm{a}, \mathrm{b}}$, Yves Vanhellemont ${ }^{\mathrm{a}}$, Barbara Lubellic, Michael de Bouw ${ }^{\mathrm{a}}$ \\ a Belgian Building Research Institute, Lab of "Retrofitting \& Heritage", Avenue P. Holoffe 21, 1342 Limelette Belgium \\ ${ }^{b}$ Royal Institute for Cultural Heritage, Parc du Cinquantenaire 1, B-1000 Bruxelles Belgium \\ ${ }_{c}$ Faculty of Architecture and the Built Environment, Delft University of Technology, Delft, The Netherlands
}

\begin{abstract}
Rising damp is a very common phenomenon and one of the most important threats for historical buildings. In this paper two non-invasive systems are studied, the first one is based on the interaction of pulsed electromagnetic waves with the porous materials and the second one is based on the active electro-osmosis principle where the natural difference in electric potential between the walls and the ground is annihilated. Within the light of the debates on the real efficiency against rising damp of such techniques in preservation of historical monuments the last 5 years, the development of such an objective test method and the outcomes of the two tested systems provided important findings for the heritage community.
\end{abstract}

Peer-review under the responsibility of the organizing committee of the ICMB21.

Keywords: rising damp, electo-osmosis, eletromagnetic techniques

\section{Introduction/Background}

Rising damp is a very common phenomenon and one of the most important threats for historical buildings (Figure 1). Lots of damage, such as biological development, soluble salts contamination and freeze-thaw cycles, are a direct result of the capillary rise of water inside the building walls [1-3]. Rising damp is also very problematic in a retrofitting project, if insulation is applied to optimize the comfort and the energy efficiency of buildings. Due to climate changes, including sea level rise and increased frequency of extreme events (flooding, intense rain), the occurrence of rising damp and its intensity are expected to increase [47]. Currently, a lot of products are available on the market but the applied methods fail often and only very invasive methods seem succeed in blocking totally the rising damp [8]. They are irreversible and they may have an impact on the stability of the building. Therefore, an efficient treatment of rising damp without these disadvantages is highly desirable.

Recent years non-invasive innovative solutions which prevent capillary rise have been developed. Two of those methods are based on electro-osmosis and on electromagnetic interaction mechanisms with masonry. Only few papers have investigated the effects of these two techniques on masonries and their effectiveness are controversial. The application of electro-osmosis method is a success in the consolidation of soils but many doubts arise for the treatment of rising damp in buildings [9-11]. There is an essential need of an accurate assessment of the efficiency of these methods. Within the research project EMERISDA [12], on-site measurements have been carried out on several sites, in order to evaluate their effectiveness [13-15].

In this paper two non-invasive systems, one based on electro-osmosis and the other one based on electromagnetic interaction with masonry are investigated, starting with a study of the involved fundamental mechanisms and followed by the assessment of their efficiency on site.

\section{Results}

In the active electro-osmotic system, the application of a direct electrical current in the moisture-saturated masonry (porous medium) generates the migration of the water from the wall (where the anode is installed) to the ground (where the cathode is installed) stopping the rising damp (Figure 1a,b). The success of the electrokinetic effects would be strongly influenced by the intensity of the voltage gradient, the pore size distribution and the $\mathrm{pH}$ of the materials. This technique has been applied in a typical Walloon house made with blocks of shale sandstone. The thickness of the wall is around $100 \mathrm{~cm}$. The assessment of the method has been done by detecting the moisture content in the wall before and after the application of the electro-osmosis systems. By gravimetric method the moisture content of drilled powder at different depths and heights in the wall, along a vertical profile, was measured. The moisture content was calculated as following:

$$
M C(\%)=\frac{\left(\text { weight }_{\text {wet }}-\text { weight }_{\text {dry }}\right)}{\text { weight }} \text { dry } .100
$$

After 6 months, the results (Figure 1) show a slight decrease of moisture content at the upper level of the wall but an increase at the bottom. Because the initial measurement was done in summer and the second one in the winter, a third one is necessary to understand the impact of seasonal moisture content fluctuations.

(C) The Author(s). This is an open access article distributed under the terms of the Creative Commons Attribution Licence (CC BY) 4.0 https://creativecommons.org/licenses/by/4.0/, which permits unrestricted use, distribution and reproduction in any medium, provided the original author and source are credited. DOI: 10.14293/ICMB210086 


\section{ICMB21}

The second system is based on the interaction of pulsed electromagnetic waves with the porous materials in masonry. The signal generates an electromagnetic field that interacts with water molecules and stops them from rising (Figure 2a,b). This technique, amongst others, has been applied in the St Martin's church in Genappe in Belgium. The results did not show a significant reduction in humidity. Moreover, after the flooding of the church after one year of measurement a major increase of the humidity has been measured, even though the masonry samples were always taken above the highest level reached by the flood. This increase has not observed in the zones with the injections at the opposite side of the church, even though the water level during the flood was equal to the level of the water in the zone with the electromagnetic device.
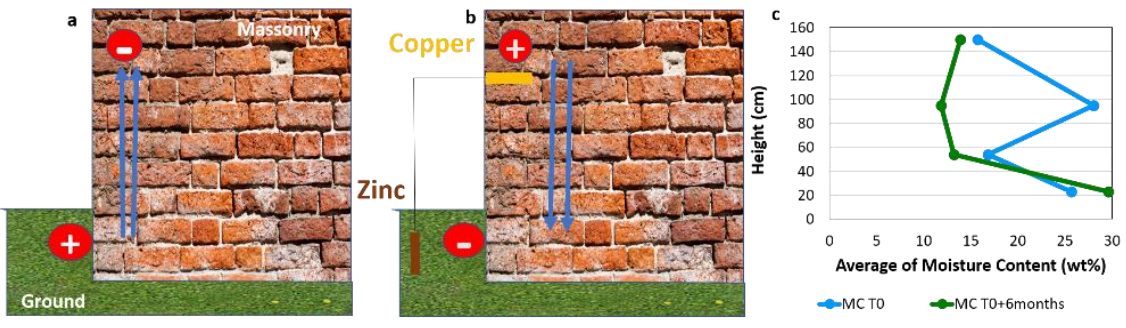

Figure 1. (a), (b) Electro-osmosis mechanism. (c) Evolution of the average moisture content along the first 30cm of the wall thickness during 6 months.

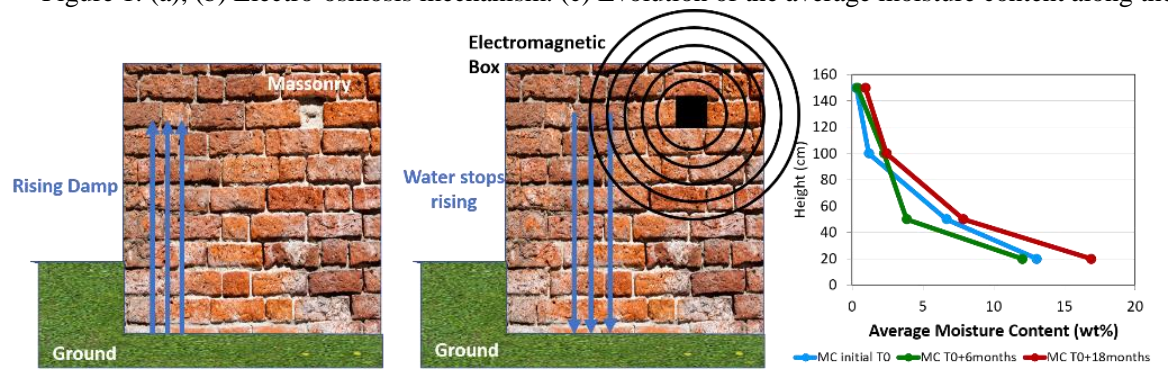

Figure 1. (a), (b) Electromagnetism mechanism. (c) Evolution of the average moisture content along the first $30 \mathrm{~cm}$ of the wall thickness during the 18 months.

Based on site field investigations and monitoring campaigns, the tests have shown that these devices did not cause any significant nor consistent decrease of the moisture content of the masonries. Moreover, the experiments done with electro-osmosis device have highlighted the possible impact of moisture content fluctuation and the need to do the measurement on the same period of the year. Within the light of the debates on the real efficiency against rising damp of such techniques in preservation and retrofitting of historical monuments that surfaced strongly during the last 5 years, the final outcome of the two tested systems provided important findings for the heritage community.

\section{References}

[1] T. Warscheid, J. Braams, Biodeterioration of stone: a review, Int. Biodeterior.Biodegrad. 46 (4) (2000) 343-368.

[2] J. Ruedrich, D. Kirchner, S. Siegesmund, Physical weathering of building stonesinduced by freeze-thaw action: a laboratory long-term study, Environ. EarthSci. 63 (7-8) (2011) 1573-1586

[3] J. Desarnaud, F.Bertrand, N.Shahidzadeh. Impact of the Kinetics of Salt Crystallization on Stone Damage During Rewetting/Drying and Humidity Cycling, Journal of Applied Mechanics (2013) 80(2):0911

[4] C. Sabbioni, P. Brimblecombe, M. Cassar, The Atlas of Climate Change Impacton European Cultural Heritage. Scientific Analysis and Management Strategies,Anthem Press, London, UK, 2010

[5] P. Brimblecombe, Mapping heritage climatologies, in: T. Bunnik, H. De Clercq,R.P.J. van Hees, H. Schellen, L. Schueremans (Eds.), Effect of Climate Changeon Cultural Heritage, WTA-Schriftenreihe, Vol. 34, WTA-Publications, Pfaffen-hofen, 2010, pp. 17-30.

[6] C.M. Grossi, P. Brimblecombe, B. Menéndez, D. Benavente, I. Harris, M. Déqué,Climatology of salt transitions and implications for stone weathering, Sci. TotalEnviron. 409 (2011) 2577-2585.

[7] IPCC, Climate change 2014: mitigation of climate change. contribution of working group III to the fifth assessment, in: O. Edenhofer, R. Pichs-Madruga, Y.Sokona, E. Farahani, S. Kadner, K. Seyboth, A. Adler, I. Baum, S. Brunner, P. Eick-emeier, B. Kriemann, J. Savolainen, S. Schlömer, C. von Stechow, T. Zwickel,J.C. Minx (Eds.), Report of the Intergovernmental Panel on Climate Change,Cambridge University Press, Cambridge, United Kingdom/New York, NY, USA,2014.

[8]E, Franzoni . Rising damp removal from historical masonries: a still open challenge. Constr Build Mater 54 (2014) 123-136.

[9] H. Wu, W. Qi, L. Hu, Q. Wen, Electro-osmotic consolidation of soil with var-able compressibility, hydraulic conductivity and electro-osmosis conductivity, Comput. Geotechnics 85 (2017) 126-138.

[10]J.K. Mitchell, K. Soga, Fundamentals of soil behavior, 2005.

[11] LM. Ottosen, I. Rörig-Dalgård. Drying brick masonry by electro-osmosis. In: Proceedings ofthe 7th International masonry conference, London 30th Oct.1st Nov. 2006

[12] (Effectiveness of Methods against Rising Damp) www.emerisda.eu

[13] B. Lubelli, R.P.J. van Hees, J. Bolhuis, Effectiveness of methods against rising damp in buildings: results from the EMERISDA project. Journal of Cultural Heritage, 31 Special Issue (2018) S15-S22

[14] Y. Vanhellemont, J. Bolhuis, M. de Bouw, S. Dubois, B. Lubelli, L. Miedema, R. van Hees. Are electrokinetic methods suitable for the treatment of rising damp? Journal of Cultural Heritage, 31 Special Issue (2018) S23-S29

[15] B.Lubelli, van Hees, R.P.J., Miedema L., Fugazzotto M., Sardella A., Bonazza A., "Electro-physical” methods to stop rising damp. Assessment of the effectiveness in two case studies, Proceedings of the International RILEM Conference on Materials, Systems and Structures in Civil Engineering, Historic masonry (Rorig-Dalgaard I. and loannou I., Eds.), 2016, pp. 195-204 